\title{
A comparative analysis of high-flux and low-flux dialysis in cervical cancer patients with obstructive renal failure showing no significantly improved renal function after catheterisation
}

\author{
Chen-li Zhang ${ }^{1}$, De-qiong Xie ${ }^{2}$, \\ Li-na Ao $\mathrm{Al}^{3}$ Lei $\mathrm{Zhu}^{4}$
}

\begin{abstract}
Objective: This study aims to compare the clinical application value of high-flux dialysis with low-flux dialysis in patients without significantly improved renal function after cervical cancer and obstructive renal failure catheterisation.

Methods: This prospective randomised study was conducted from January 2018 to December 2019. Eighty cervical cancer patients with obstructive renal failure who showed no significant renal function improvement after catheterisation were randomised into two groups ( $n=40$ in each group) in the Second People's Hospital of Yibin City. High-flux and low-flux dialysis were employed in the experimental group and the control group, respectively. Treatments in both groups were provided every other day, with the whole course lasting one week. Data were recorded before and after dialysis included inflammatory factors such as IL-6, CRP and TNF-a, large and moderate molecular toxins (e.g., B2 micro-globulin, parathyrin (PTH) and cysteine protease inhibitor). Renal function changes during the dialysis were also recorded. Afterwards, the two groups were compared regarding the overall efficacy.

Results: Both the experimental group and the control group experienced a significant decrease in IL-6, CRP, TNF-a, B2 micro-globulin, PTH and cysteine protease inhibitor, with the decrease in the experimental group being more evident $(p<0.05)$. After dialysis was completed, the experimental group restored renal function indicators such as Cre, CysC and serum $\mathrm{K}+$ levels more quickly than the control group $(p<0.05)$. The effective rate was $100 \%$ for the experimental group and $87.5 \%$ for the control group. The intragroup difference in the efficacy.was significant.

Conclusions: High-flux dialysis appears to be more beneficial for cervical cancer patients with obstructive renal failure, showing no significant improvement in renal function after catheterisation. It restored renal function more quickly, had more radical draining of inflammatory factors and large and moderate molecular toxins, and had a higher overall effective rate.
\end{abstract}

KEYWORDS: Cervical cancer, High-flux dialysis, Obstructive nephropathy, Treatment.

doi: https://doi.org/10.12669/pjms.37.4.3515

How to cite this:

Zhang C, Xie DQ, Ao L, Zhu L. A comparative analysis of high-flux and low-flux dialysis in cervical cancer patients with obstructive renal failure showing no significantly improved renal function after catheterisation. Pak J Med Sci. 2021;37(4):1014-1019. doi: https://doi.org/10.12669/pjms.37.4.3515

This is an Open Access article distributed under the terms of the Creative Commons Attribution License (http://creativecommons.org/licenses/by/3.0), which permits unrestricted use, distribution, and reproduction in any medium, provided the original work is properly cited.

Correspondence:

Chen-li Zhang,

Department of Nephrology,

The Second People's Hospital of Yibin City, Yibin,

Sichuan, 644000, P.R. China.

Email: ttdo19@163.com

* Received for Publication:

* $1^{\text {st }}$ Revision Received:

* $2^{\text {nd }}$ Revision Received:

* Final Revision Accepted: *
August 19, 2020

October 17, 2020

February 26, 2021

March 5, 2021

\section{INTRODUCTION}

Cervical cancer is a common gynaecological cancer with high morbidity. It is the fourth most common malignant tumour among women worldwide, and its morbidity is much higher in developing countries than in the developed ones. ${ }^{1}$ For advanced cervical cancer, renal function will be inevitably impaired with hydronephrosis 
caused by all sorts of factors, ${ }^{2}$ including extensive hysterectomy, pelvic lymphadenectomy, damage of pelvic chemoradiotherapy to the ureter, and direct invasion of the tumour to the ureter. Renal function impairment is usually postrenal and obstructive. Unlike primary renal diseases, it usually features acute onset and fast progression and may lead to renal failure, electrolyte disturbance and toxicant build-up within a short period. Though immensely harmful, renal function impairment can quickly recover once the obstruction is relieved by such surgical intervention measures as ureter catheterisation. ${ }^{3}$ However, a small portion of patients may appear to have a slight improvement in post-surgical renal function so that they may still need further haemodialysis to improve the renal function and electrolyte disturbance, correct the state of internal toxicant accumulation, and get steadily through the critical stage to fight for a better chance for subsequent treatment.

This study aimed to further illustrate the clinical application value of high-flux dialysis by comparing the clinical effects of high-flux and lowflux dialysis in dealing with cervical cancer patients that have insignificantly improved renal function after obstructive renal failure catheterisation.

\section{METHODS}

This is a prospective, randomised controlled study. From January 2018 to December 2019, 80 patients were enrolled and then randomised into two groups ( $n=40$ in each group) in the Second People's Hospital of Yibin City. Patients in the experimental group aged between 46 and 67 years old with an average age of $56.23 \pm 6.84$ years. It required from 1.3 to 3 years to develop from cervical cancer to obstructive renal failure (average: $2.32 \pm$ 0.49 years). By contrast, control group individuals aged between 44 and 66 years old with an average age of $56.00 \pm 8.14$ years. The disease course lasted between 1.4 and 2.7 years (average: $2.33 \pm 0.36$ years). The general data of both groups of the patient (Table-I) were comparable and did not differ significantly $(p>0.05)$.

Ethical approval: The study was approved by the Institutional Ethics Committee of the Second People's Hospital on August 15, 2020, of Yibin City, and written informed consent was obtained from all participants

Inclusion criteria:

1. Patients with advanced cervical cancer, combined with obstructive renal failure, showed no significant improvement in renal function after ureteral catheterisation (serum creatinine $>707 \mu \mathrm{mol} / \mathrm{L}$ ) and serum potassium $>6.5$ $\mathrm{mmol} / \mathrm{L}$ and compliance with haemodialysis criteria. $^{4}$

2. Patients who were compliant and could complete the study.

3. Patients who agreed to join the study and provided informed consent.

\section{Exclusion criteria:}

1. Patients with significantly improved renal function after catheterisation (serum creatinine $>600 \mu \mathrm{mol} / \mathrm{L}$; serum potassium $>6.0 \mathrm{mmol} / \mathrm{L}$ ) did not need dialysis.

2. Severely consumed patients with bad general conditions.

3. Patients with other mental diseases, imperfect compliance or inability to participate in the study until it ended.

4. Patients turning to other therapies due to improperly indwelling catheter or unsuccessful catheterisation.

Treatment Catheterisation Methods: The patient was asked to lie in the lithotomy position to accept topical anaesthesia, sterilisation and surgical draping before the transurethral ureteroscope was inserted into the bladder. Once the ureteral orifice was located, a Zebra urological guidewire was put into the ureter to guide the stent into the ureter. When the stent was adjusted to a satisfactory position, the other stent was indwelled adequately in the same way. An abdominal X-ray was performed immediately after the operation was done to determine the locations of the stents. Stents were replaced every six months afterwards.

Types of Haemodialysis Methods - Experimental group: High-flux dialysis was chosen. A German Braun 710207t haemodialysis machine was used to perform the dialysis with bicarbonate solution as the dialysate. The dialyzer model was an FX80 polysulfone membrane with an ultrafiltration coefficient of $46 \mathrm{ml} /(\mathrm{mm} \mathrm{Hg} \mathrm{h})$, a membrane area of $1.8 \mathrm{~m}^{2}$. The dialysis was done every other day for four hour each time.

Control group: Low-flux haemodialysis was selected with an FX8 polysulfone dialyzer. The ultrafiltration coefficient was $12 \mathrm{ml} /(\mathrm{mm} \mathrm{Hg} \mathrm{h})$ $(1 \mathrm{~mm} \mathrm{Hg}=0.1333 \mathrm{kPa})$, and the membrane area was $1.0 \mathrm{~m}^{2}$. The dialysis was done every other day for four hour each time. Both groups received oneweek dialytic treatment.

Indicators of blood microinflammation and renal function: Fasting blood in the morning was collected from all patients before dialysis. One week after 
Table-I: A comparison of patients' general data in the two groups $(\bar{X} \pm S), \mathrm{n}=40$.

\begin{tabular}{lcccc}
\hline Indicator & Experimental & Control & $t / \chi^{2}$ & $P$ \\
\hline Age (year) & $56.23 \pm 6.84$ & $56.00 \pm 8.14$ & 0.14 & 0.89 \\
Course (year) & $2.32 \pm 0.49$ & $2.33 \pm 0.36$ & 0.10 & 0.92 \\
Cause & & & & \\
Direct invasion (no, \%) & $13(32.5 \%)$ & $15(37.5 \%)$ & 0.22 & 0.17 \\
Pelvic chemoradiotherapy (no, \%) & $18(45 \%)$ & $18(45 \%)$ & 0.00 & 0.18 \\
Pelvic surgery (no, \%) & $9(22.5)$ & $7(17.5)$ & 0.31 & 0.19 \\
\hline
\end{tabular}

Note: $\mathrm{p}>0.05$.

dialysis to examine changes in microinflammation reaction, large and moderate molecular toxins and renal function. The microinflammation reaction evaluation included IL-6, CRP and TNF-a. As for large- and moderate-molecular toxins, such indicators as $\beta 2$ micro-globulin, parathyrin $(\mathrm{PTH})$ and cysteine protease inhibitor were examined to assess their changes before and after dialysis. For renal function assessment, morning blood was sampled before dialysis, and every day after dialysis, it was tested with a fully automatic biochemical analyser. The analysis covered creatinine, urea nitrogen and cystatin. The time required for renal function indicators to recover was recorded, and the intragroup difference in this respect was compared. Efficacy assessment indicators:

Excellent: Both BUN and Cr significantly improved after treatment, and almost all clinical symptoms disappeared.

Effective: After treatment, BUN and $\mathrm{Cr}$ improved somewhat, and the clinical symptoms were alleviated.

Ineffective: No significant improvement was witnessed in the clinical symptoms; $\mathrm{BUN}$ and $\mathrm{SCr}$ revealed no evident changes. The effective rate $=$ (excellent + effective) $/$ total cases $\times 100 \%$. The time for treatment and renal function improvement was recorded.

Statistical analysis: All data were processed using SPSS 20.0. Metrological data were presented as $\bar{X}^{ \pm}$S. Data analysis between the experimental and the control groups was checked with an independent-samples t-test, whereas the rate comparison was checked with $\chi^{2} . P<.05$ was considered statistically significant.

\section{RESULTS}

Indicators of microinflammation reaction: Both the experimental group and the control group displayed a significant decrease in indicators, such as IL-6, CRP and TNF- $\alpha$ after treatment was completed $(p$ $=.00)$. However, the experimental group's decrease appeared to be more significant than in the control group (IL-6, CRP: $p=.01$; TNF-a, $p=0.02$ ) (Table-II). Indicators of changes in large- and moderatemolecular toxins: In both the experimental group and the control group, $\beta 2$ micro-globulin, PTH and cysteine protease inhibitor presented a significant

Table-II: A comparison of inflammatory factors in the experimental and control groups before and after treatment $(\bar{X} \pm S), n=40$.

\begin{tabular}{|c|c|c|c|c|c|c|c|c|c|c|c|c|}
\hline \multirow{2}{*}{$\begin{array}{l}\begin{array}{l}\text { Observed } \\
\text { indicator }\end{array} \\
\text { Group }\end{array}$} & \multicolumn{4}{|c|}{$I L-6(n g / L)$} & \multicolumn{4}{|c|}{$C R P(m g / L)$} & \multicolumn{4}{|c|}{$T N F-a(n g / L)$} \\
\hline & Before* & After $\Delta$ & $t$ & $p$ & Before ${ }^{*}$ & After $\Delta$ & $t$ & $p$ & Before & After $\Delta$ & $t$ & $p$ \\
\hline $\begin{array}{l}\text { Experi- } \\
\text { mental } \Delta\end{array}$ & $\begin{array}{c}15.43 \pm \\
5.32\end{array}$ & $\begin{array}{c}8.97 \pm \\
2.24\end{array}$ & 7.08 & 0.00 & $\begin{array}{l}3.37 \pm \\
0.15\end{array}$ & $\begin{array}{c}2.01 \pm \\
0.47\end{array}$ & 17.43 & 0.00 & $\begin{array}{c}47.52 \pm \\
13.81\end{array}$ & $\begin{array}{l}20.37 \pm \\
7.24\end{array}$ & 11.01 & 0.00 \\
\hline Control $\Delta$ & $\begin{array}{c}15.33 \pm \\
4.68\end{array}$ & $\begin{array}{c}10.23 \pm \\
1.72\end{array}$ & 6.47 & 0.00 & $\begin{array}{c}3.41 \pm \\
0.82\end{array}$ & $\begin{array}{c}2.25 \pm \\
0.33\end{array}$ & 8.30 & 0.00 & $\begin{array}{l}46.73 \pm \\
12.55\end{array}$ & $\begin{array}{c}23.72 \pm \\
5.48\end{array}$ & 10.63 & 0.00 \\
\hline $\mathrm{t}$ & 0.09 & 2.82 & & & 0.30 & 2.64 & & & 0.27 & 2.33 & & \\
\hline$p$ & 0.93 & 0.01 & & & 0.76 & 0.01 & & & 0.79 & 0.02 & & \\
\hline
\end{tabular}

Note: before $=$ before dialysis but after catheterisation; after $=1$ week after the dialysis, ${ }^{*} \mathrm{p}>.05, \Delta \mathrm{p}<05$. 
Chen-li Zhang et al.

Table-III: An intragroup comparison of large and moderate molecular toxins before and after the treatment $(\bar{X} \pm S), \mathrm{n}=40$

\begin{tabular}{|c|c|c|c|c|c|c|c|c|c|c|c|c|}
\hline \multirow{2}{*}{$\begin{array}{l}\begin{array}{l}\text { Observed } \\
\text { indicator }\end{array} \\
\text { Group }\end{array}$} & \multicolumn{4}{|c|}{$\beta_{2}$ micro-globulin $(\mathrm{mg} / \mathrm{L})$} & \multicolumn{4}{|c|}{ PTH $(p g / m l)$} & \multicolumn{4}{|c|}{ Cysteine protease inhibitor $(\mathrm{mmol} / \mathrm{L})$} \\
\hline & Before* & After $\Delta$ & $t$ & $p$ & Before* & Afters & $t$ & $p$ & Before* & After $\Delta$ & $t$ & $p$ \\
\hline $\begin{array}{l}\text { Experi- } \\
\text { mental } \Delta\end{array}$ & $\begin{array}{c}19.23 \pm \\
5.02\end{array}$ & $\begin{array}{c}9.07 \pm \\
3.24\end{array}$ & 10.75 & 0.00 & $\begin{array}{c}667.20 \pm \\
34.47\end{array}$ & $\begin{array}{c}431.21 \pm \\
23.78\end{array}$ & 35.64 & 0.00 & $\begin{array}{c}5.52 \pm \\
1.24\end{array}$ & $\begin{array}{c}2.13 \pm \\
0.72\end{array}$ & 14.95 & 0.00 \\
\hline Control $\Delta$ & $\begin{array}{c}19.41 \pm \\
4.77\end{array}$ & $\begin{array}{c}10.81 \pm \\
3.71\end{array}$ & 9.00 & 0.00 & $\begin{array}{c}661.94 \pm \\
33.46\end{array}$ & $\begin{array}{c}462.35 \pm \\
31.07\end{array}$ & 27.65 & 0.00 & $\begin{array}{c}5.63 \pm \\
1.43\end{array}$ & $\begin{array}{c}2.47 \pm \\
0.43\end{array}$ & 13.38 & 0.00 \\
\hline $\mathrm{t}$ & 0.16 & 2.23 & & & 0.69 & 5.03 & & & 3.37 & 2.56 & & \\
\hline $\mathrm{p}$ & 0.87 & 0.03 & & & 0.49 & 0.00 & & & 0.74 & 0.01 & & \\
\hline
\end{tabular}

Note: before $=$ before dialysis but after catheterisation; after $=1$ week after the dialysis, ${ }^{*} \mathrm{p}>.05, \Delta \mathrm{p}<.05$

decrease after the treatment. The differences were significant $(p=0.00)$, with those in the experimental group being more striking. The intragroup differences were also significant ( $\beta 2$ micro-globulin: $p=0.03$; PTH: $p=0.00$; and cysteine protease: $p=$ 0.01) (Table-III).

Indicators of renal function change: Both the experimental and the control groups quickly recovered renal function after treatment. The experimental group recovered more quickly than the control group in all related indicators (e.g. $\mathrm{Cre}$, CysC and serum $\mathrm{K}+$ ) except for Ure, and the intragroup differences were significant (Cre: $p=.03$; CysC: $p=.01$; and serum $\mathrm{K}^{+}: p=.02$ ) (Table-IV).

Effective rate comparison: One week after treatment was completed, the experimental group obtained an effective rate of $100 \%$, whereas the effective rate in the control group was $87.5 \%$, with 35 cases being effectively treated. The intragroup difference in the effective rate was significant, with the experimental group being more effectively treated than the control group $(p=0.02)($ Table-V).

\section{DISCUSSION}

In recent years, advanced cervical cancer treatment regimens are inclined to be more crossdisciplined and integrated. ${ }^{5}$ A combined regimen of radiotherapy, chemotherapy, dialysis and surgical intervention helps reduce patients' pain, prolonging their survival time and improving their quality of life..$^{6-8}$ In treating advanced cervical cancer, the diagnosis and treatment of combined urologic diseases is sometimes conventional. However, other occasions are severe and demand emergency intervention to remove the causative factor. ${ }^{9}$ No matter what kind of therapy is chosen

Table-IV: An intragroup comparison of time for restoring the renal function indicators $\left(\bar{X}^{ \pm} S\right), n=40$.

\begin{tabular}{lcccc}
\hline Indicator & Ure $(d)$ & Cre $(d)^{*}$ & CysC $(d)^{*}$ & ${\left.\text { Serum } K^{+} d\right)^{*}}^{*}$ \\
\hline Experimental & $1.89 \pm 0.81$ & $2.15 \pm 0.93$ & $1.68 \pm 0.67$ & $2.84 \pm 0.62$ \\
Control & $1.86 \pm 0.78$ & $2.79 \pm 0.59$ & $2.07 \pm 0.71$ & $3.13 \pm 0.45$ \\
$\mathrm{t}$ & 0.17 & 3.75 & 2.53 & 2.39 \\
$\mathrm{p}$ & 0.86 & 0.03 & 0.01 & 0.02 \\
\hline
\end{tabular}

${ }^{*} \mathrm{p}<.05$.

Table-V: A comparison of the experimental and control groups' effective rate $\left(\overline{X^{ \pm}} \mathbf{S}\right), n=40$.

\begin{tabular}{lcccc}
\hline Group & Excellent & Effective & Ineffective & Effective rate $^{*}$ \\
\hline Experimental & 33 & 7 & 0 & $100 \%$ \\
Control & 26 & 9 & 5 & $87.5 \%$ \\
$x^{2}$ & & & & 5.33 \\
$\mathrm{p}$ & & & & 0.02 \\
\hline
\end{tabular}

$\begin{array}{lllll}\text { Pak J Med Sci July - August } 2021 & \text { Vol. } 37 & \text { No. } 4 & \text { www.pjms.org.pk } 1017\end{array}$ 
during cervical cancer treatment, be it surgery, post-surgical radiotherapy or chemotherapy, the ureter within therapeutic range is always impaired, though in varying degrees. The consequences of such impairment include hydronephrosis, abnormal renal function and obstructive renal failure. ${ }^{10,11}$

Some patients fail to show significantly improved renal function after a urethral catheter is placed to relieve the obstruction. ${ }^{12}$ Their severe symptoms of the internal environment disturbance such as azotaemia and hyperkalaemia are not corrected as soon as expected without significant changes in creatinine, urea nitrogen or serum potassium on the following day after the ureteral stent is placed. ${ }^{13}$ For such patients, haemodialysis should be performed to decelerate the rapidly collecting toxins within the body and help patients to handle the critical stage, according to our experience. In such cases, haemodialysis appears to have a confirmative effect, as patients can recover sooner. There are two types of haemodialysis: high-flux and low-flux. ${ }^{14}$ The quality of haemodialysis remains closely linked to the way they are implemented. ${ }^{15}$ Obstructive renal failure derived from cervical cancer presents both chronic renal functional compensation and characteristics of an acute attack. For postrenal obstructive renal disease, abnormal pressure within the renal pelvis causes a rapid inhibition of glomerular filtration function but does not change the glomeruli filtering membrane permeability. As a result, toxic substances within the human body quickly accumulate, especially those large and moderate molecular substances like $\beta_{2}$ microglobulin, PTH and cysteine protease inhibitor. They further affect the recovery of patients' renal function. High-flux dialysis uses a high-flux membrane in haemodialysis. ${ }^{16}$ It has a significantly higher flux than the common one and can better eradicate the moderate and large molecular solutes. The present study verified that the $\beta_{2}$ micro-globulin, PTH and cysteine protease inhibitor decreased more sharply in the experimental group applied with high-flux dialysis than in the control group. The intragroup differences are significant $(p<.05)$, indicating highflux dialysis appears to be more advantageous in eradicating the large and moderate molecular toxins among cervical cancer patients whose renal function is not significantly improved after obstructive renal failure catheterisation.

The study by Svara further implies ${ }^{17}$ that highflux dialysis using biocompatible membrane can better protect patients' remnant renal function, reduce the inflammatory response and improve the human body's nutritional status. Compared with common dialysis, high-flux dialysis may greatly reduce morbidity among patients. ${ }^{18}$ Our study also suggests that the experimental group has significantly lower IL-6, CRP and TNF-a than the control group after dialysis is completed. A decrease in inflammatory factors promotes renal function restoration and prognosis. Also, Cre, CysC and serum $\mathrm{K}+$ are restored more quickly in the experimental group than in the control group, and the intragroup differences are statistically significant.

Whether the haemodialysis can eliminate large and moderate molecular substances in the blood directly affects the therapeutic effect. ${ }^{19}$ This study demonstrates a $100 \%$ effective rate for the experimental group but an $87.5 \%$ for the control group. This difference is significant $(\mathrm{p}=.02)$. Moreover, patients in the experimental group recovered their renal function significantly more quickly than those in the control group $(p<.05)$.

Cervical cancer-induced renal failure is essentially different from the functional failure of thekidney itself. For the former, once the obstruction is removed, most patients recover within a short period. For patients in our experimental group, their renal function improved within 3-4 days after completing dialysis. However, despite improved renal function, the indwelling stent should remain and be regularly replaced. Borboroglu et al. ${ }^{20}$ confirmed in their study of cervical cancer patients with renal dysfunction that indwelling stents should replace every 2 to 4 months later. As constant progress has been made in material science, the interval of an indwelling stent made of various materials has been extended from the original to four months to the present one year, though at a high cost. The stents may be chosen as per the patients' specific conditions.

Limitations of the study: The present study also has some limitations. First, dialysis is set to last one week. The time may be further shortened, and a more individualised haemodialysis plan may be drafted with renal function recovery as a research focus. By determining the decrease in inflammatory factors and large and moderate molecular toxins, it is hoped to reduce the treatment period and cost. Second, the samples are insufficient, so the sample size may be further expanded to achieve a large sample clinical analysis. Third, this study lacks a follow-up visit. Although the patients' symptoms are improved through a combination of catheter- 
aided obstruction removal with dialysis, a large difference exists regarding the toxin eradicating effect in vivo of the two types of dialysis. We are also carrying outd additional studies to analyse the long-term effect of patients after receiving those two different types of dialysis, including the differences in long-term damage of obstructive renal failureinduced toxin build-up to other tissues and organs. Through the study, we will further elucidate the long-term benefits of high-flux dialysis to patients.

\section{CONCLUSION}

Taken together, high-flux dialysis enables cervical cancer patients without significantly improved renal function after obstructive renal failure catheterisation to recover more quickly. Their internal inflammatory factors and moderate/ large molecular toxins are more radically drained. The general efficiency of high-flux dialysis is higher. Therefore, for patients showing no significant improvement in renal function after being catheterised, high-flux dialysis should be administered in time to help patients handle the critical stage.

\section{Funding: None.}

\section{Declaration of conflicting interest: None.}

\section{REFERENCES}

1. $\mathrm{Vu} \mathrm{M}, \mathrm{Yu} \mathrm{J}$, Awolude OA, Chuang L. Cervical cancer worldwide. Curr Probl Cancer. 2018;42(5):457-465. doi: 10.1016/j. currproblcancer.2018.06.003

2. Hockel M, Wolf B, Schmidt K, Mende M, Aktas B, Kimmig R, et al. Surgical resection based on ontogenetic cancer field theory for cervical cancer: Mature results from a single-center, prospective, observational, cohort study. Lancet Oncol. 2019;20(9):1316-1326. doi: 10.1016/S1470-2045(19)30389-4

3. Tan S, Tao Z, Bian X, Zhao Y, Wang N, Chen X, et al. Ureteral stent placement and percutaneous nephrostomy in the management of hydronephrosis secondary to cervical cancer. Eur J Obstet Gynecol Reprod Biol. 2019;241:99-103. doi: 10.1016/j.ejogrb.2019.08.020

4. Queeley GL, Campbell ES, Ali AA. Assessing the level of patient-specific treatment recommendations in clinical practice guidelines for hemodialysis vascular access in the United States. Am Health Drug Benefits. 2018;11(5):223-230.

5. Li N, Tian YW, Xu Y, Meng DD, Gao L, Shen WJ, et al. Combined Treatment with Autologous CIK Cells, Radiotherapy and chemotherapy in advanced cervical cancer. Pathol Oncol Res. 2019;25(2):691-696. doi: 10.1007/s12253-018-0541-2

6. Costantini B, Vizzielli G, Fanfani F, D'Addessi A, Ercoli A, Avenia $\mathrm{N}$, et al. Urologic surgery in gynecologic oncology: A large singleinstitution experience. Eur J Surg Oncol. 2014;40(6):756-761. doi: 10.1016/j.ejso.2014.01.020

7. Gadducci A, Cosio S. Neoadjuvant chemotherapy in locally advanced cervical cancer: Review of the literature and perspectives of clinical research. Anticancer Res. 2020;40(9):48194828. doi: 10.21873 /anticanres.14485

8. Yoshida K, Kajiyama H, Yoshihara M, Tamauchi S, Ikeda Y, Yoshikawa $\mathrm{N}$, et al. The role of additional hysterectomy after concurrent chemoradiation for patients with locally advanced cervical cancer. Int J Clin Oncol. 2020;25(2):384-390. doi: 10.1007/ s10147-019-01551-6
9. Zigras T, Lennox G, Willows K, Covens A. Early cervical cancer: Current dilemmas of staging and surgery. Curr Oncol Rep. 2017;19(8):51. doi: 10.1007/s11912-017-0614-5

10. Ozyer U, Dirim A. Tandem ureteral stents in the management of double-J stent dysfunction in gynecological malignancies. Diagn Interv Imaging. 2017;98(9):601-608. doi: 10.1016/j.diii.2017.07.005

11. Maguire PJ, Sobota A, Mulholland D, Ryan JM, Gleeson N. Incidence, management, and sequelae of ureteric obstruction in women with cervical cancer. Support Care Cancer. 2020;28(2):725730. doi: 10.1007/s00520-019-04851-9

12. Tan S, Tao Z, Bian X, Zhao Y, Wang N, Chen X, et al. Ureteral stent placement and percutaneous nephrostomy in the management of hydronephrosis secondary to cervical cancer. Eur J Obstet Gynecol Reprod Biol. 2019;241:99-103. doi: 10.1016/j. ejogrb.2019.08.020

13. Pergialiotis V, Bellos I, Thomakos N, Haidopoulos D, Perrea DN, Kontzoglou K, et al. Survival outcomes of patients with cervical cancer and accompanying hydronephrosis: A systematic review of the literature. Oncol Rev. 2019;13(1):387. doi: 10.4081/ oncol.2019.387

14. Han S, Yang K, Sun J, Liu J, Zhang L, Zhao J. Proteomics investigations into serum proteins adsorbed by high-flux and low-flux dialysis membranes. Proteomics Clin Appl. 2017;11(1112):11-12. doi: $10.1002 /$ prca.201700079

15. Morena M, Jaussent A, Chalabi L, Leray-Moragues H, Chenine $\mathrm{L}$, Debure A, et al. Treatment tolerance and patient-reported outcomes favor online hemodiafiltration compared to high-flux hemodialysis in the elderly. Kidney Int. 2017;91(6):1495-1509. doi: 10.1016/j.kint.2017.01.013

16. Maduell F, Rodas L, Broseta JJ, Gomez M, Xipell Font M, Molina A, et al. High-permeability alternatives to current dialyzers performing both high-flux hemodialysis and postdilution online hemodiafiltration. Artif Organs. 2019;43(10):1014-1021. doi: 10.1111/aor.13480

17. Svara F, Lopot F, Valkovsky I, Pecha O. Phosphorus removal in low-flux hemodialysis, high-flux hemodialysis, and hemodiafiltration. ASAIO J. 2016;62(2):176-181. doi: 10.1097/ MAT.0000000000000313

18. Lu W, Ren C, Han X, Yang X, Cao Y, Huang B. The protective effect of different dialysis types on residual renal function in patients with maintenance hemodialysis: A systematic review and meta-analysis. Med (Baltim). 2018;97(37):e12325. doi: 10.1097/MD.0000000000012325

19. Knehtl M, Jakopin E, Dvorsak B, Bevc S, Ekart R, Hojs R. The effect of high-flux hemodialysis and post-dilution hemodiafiltration on platelet closure time in patients with end stage renal disease. Hemodial Int. 2019;23(3):319-324. doi: 10.1111/hdi.12756

20. Borboroglu PG, Kane CJ. Current management of severely encrusted ureteral stents with a large associated stone burden. J Urol. 2000;164(3Pt1):648-650. doi: 10.1097/00005392-200009010-00007

\section{Authors' Contributions:}

CZ and DX designed this study and prepared this manuscript and are responsible and accountable for the accuracy or integrity of the work.

LA collected and analysed clinical data.

LZ significantly revised this manuscript.

Authors:

1. Chen-li Zhang,

2. De-qiong Xie,

3. Li-na Ao,

4. Lei Zhu,

1-4: Department of Nephrology,

The Second People's Hospital of Yibin City,

Yibin, Sichuan, 644000,

P.R. China. 